\title{
Improvement of laser induced breakdown spectroscopy signal for sodium chloride solution
}

\author{
Hanin Athirah Harun*, Roslinda Zainal \\ Department of Physics, Faculty of Science, Universiti Teknologi Malaysia, 81310 UTM Johor Bahru, Johor, Malaysia \\ * Corresponding author: hathirah2@live.utm.my
}

\section{Article history}

Received 3 May 2018

Revised 25 August 2018

Accepted 11 September 2018

Published Online 25 October 2018

\begin{abstract}
Laser induced breakdown spectroscopy (LIBS) is one of the analytical spectroscopy technique used in determining elemental composition of solid, liquid or gas sample using high energy laser pulse. However, LIBS technique associated with liquid sample often suffers from strong splashing and shockwave, thereby affecting the LIBS experiment repeatability and performance analysis. Therefore, a simple and quick-freeze sample pre-treatment approach using Peltier Thermoelectric Cooler (TEC) to solidify the water is applied to maintain the inherent homogeneity and chemical composition of the initial liquid sample before each LIBS analysis. This approach successfully solidified and maintained the liquid sample at its freezing point throughout the LIBS signal acquisition process. In this work, the qualitative analysis liquid samples and its solidified form, consisting of 0.5 , $1.0,1.5$ and $2.0 \mathrm{~mol} / \mathrm{L}$ sodium chloride $(\mathrm{NaCl})$ were determined under similar experimental conditions by using LIBS. Plasmas were produced by focusing the output of Nd: YAG laser (1064nm, $6 \mathrm{~ns}$ and $1 \mathrm{~Hz}$ ) on the surface of the bulk $\mathrm{NaCl}$ solution and its solidified form. LIBS signatures for sodium (Na) and chlorine $(\mathrm{Cl})$ atomic emission lines (589.00 and $499.55 \mathrm{~nm}$, respectively) were collected for estimating sodium and chlorine depositions in $\mathrm{NaCl}$ solutions to indicate correlation between their assay and LIBS measurements. For solidified sample, $\mathrm{Na}$ and $\mathrm{Cl}$ showed improved signal-to-noise ratio and limits of detection $(47.8 \%$ and $8.8 \%$, respectively) without the difficulties usually associated with liquid samples, demonstrating the benefits of this sample pre-treatment approach.
\end{abstract}

Keywords: Laser induced breakdown spectroscopy, liquid sample, thermoelectric cooler, sodium chloride, LIBS signal

(c) 2018 Penerbit UTM Press. All rights reserved

\section{INTRODUCTION}

Laser induced breakdown spectroscopy (LIBS) is a laser based analytical method, capable of providing rapid multiple elemental analysis in any state of matter. Eventhough LIBS technique has a limited detection sensitivity (lower parts-per-million range), other analytical atomic spectrometry methods including inductively coupled plasma mass spectroscopy (ICP-MS) and inductively coupled plasma atomic emission spectroscopy (ICP-AES) tend to have higher operational and functional cost, whereas atomic absorption spectroscopy (AAS) method is more time consuming [1].

LIBS operates by focusing high energy pulsed laser onto a sample surface. Small volume of the sample is vaporized and ionized, thereby forming highly energetic plasma with high temperature. During plasma cooling, electrons of atoms and ions at excited state fall down into natural ground state, causing the plasma to emit discrete spectral peaks that are important in providing sample's compositional information [2]. Due to LIBS various advantages such as ability to analyze various type of sample, real time data collection, experimental surrounding flexibility, remote material assessment and simultaneous multi element detection, this technique has been widely used in various field $[2,3]$. Recent LIBS applications includes works related to materials science [4], coal analysis for power plants application [5], arts and artifacts cultural heritage [6], agriculture [7], biological samples [8], and others.

Regardless LIBS various contributions, especially in providing measurements for solid samples, LIBS analysis inside the liquid bulk or on its surface could cause a few challenges such as shorter plasma duration, splashing and surface ripple [9]. In addition, all of these drawbacks could lead to poorer figures of merit (including precision, sensitivity and limits of detection) when compared to solid LIBS analysis [10]. To overcome these challenges, various methods such as horizontal [11] and vertical liquid jet system for laminar flow [12, 13], liquid to aerosol conversion [14, 15], liquid sample in droplet form [16-18], and liquid to solid matrix layer conversion [19, 20] were implied in previous study. Despite that, majority of these approches implicate a more complex experimental configuration, often deemed as non practical for real time on site measurements and unsuitable for a limited or hazardous sample [21].

In contrast, liquid to solid sample phase conversion by freezing is one of the uncomplicated sample preparation methods in reducing splashing, thereby leading to emission enhancement and improved LIBS measurement [22, 23]. Meanwile, maintaining the sample temperature is vital when dealing with frozen sample in order to provide high LIBS measurement accuracy as the sample temperature is closely related to ablation rate and plasma intensity [24]. Since liquid nitrogen is more favorable for the purpose of freezing the sample [22, 23, 25], maintaining the sample temperature especially in room temperature where the experiment is usually conducted is quite difficult as the sample temperature could drop quite drastically.

Therefore, in the present paper we intend to demonstrate the feasibility of using Thermolectric Cooler (TEC) to facilitate a more effective liquid to solid sample phase conversion approach for LIBS application where the sample remained in its freezing phase during 
data acquisition. The Peltier thermoelectric cooler is a thermoelectric energy conversion device that employs the Peltier effect by delivering heat energy from one side of the device (heat source) to the other side (heat sink). Peltier effect take place when two different semiconductor materials which are n-type and p-type, joined together with electric current passing through its junction, thereby either cooling or heating the junction [26]. Several key advantages of using this device are high efficiency, no maintenance or complex water distribution pipes requirements, longer lifetime, environmental friendly, satisfactory performance, noiseless and lighter weight [27].

The aim of this study is to evaluate the ability of this sample pretreatment method in providing better LIBS measurements for different concentration of sodium chloride $(\mathrm{NaCl})$ solution while maintaining the inherent homogeneity and chemical composition of the initial liquid sample. Hence, this work focused on investigating the LIBS spectra, limit of detection (LOD) and signal-to-noise ratio (SNR) in solidified samples and comparing it to that acquired with LIBS performed on the surface of liquid $\mathrm{NaCl}$ solution.

\section{EXPERIMENTAL WORK}

\section{Materials}

In this study, $\mathrm{NaCl}$ solutions with four different concentrations $(0.5,1.0,1.5$ and $2.0 \mathrm{~mol} / \mathrm{L})$ was analyzed with LIBS in two different ways: first, as liquid specimens, and second as frozen $\mathrm{NaCl}$ solutions. The $\mathrm{NaCl}$ solution samples was chosen to test the ability of the TEC in freezing the sample as $\mathrm{NaCl}$ solution has lower freezing point when compared to normal water. The specimens were prepared from $99.9 \%$ vacuum salt diluted in distilled water. The samples were then stirred to ensure homogeneity. For each experiment, $1.5 \mathrm{ml}$ of the sample solution was placed inside an aluminium foil sample holder as ahown in Fig. 1.

\section{Thermoelectric cooler}

Fig. 1 shows the Peltier TEC device consisted of a Thermoelectric cooler (Peltier module TEC1-12715) and an aluminum heat sink with two attached cooling fans to control the heat dissipation. A power supply (PSU S-360-12) with DC output of 0-12 V and $30 \mathrm{~A}$ was selected due to its compatibility to work with Peltier device (maximum voltage: $15.4 \mathrm{~V}$ and maximum current: $15 \mathrm{~A}$ ). Meanwhile, the grayish substance is the heat sink compound, which is used as an interface between the Peltier device and the heat sink, thereby maximizing heat transfer.

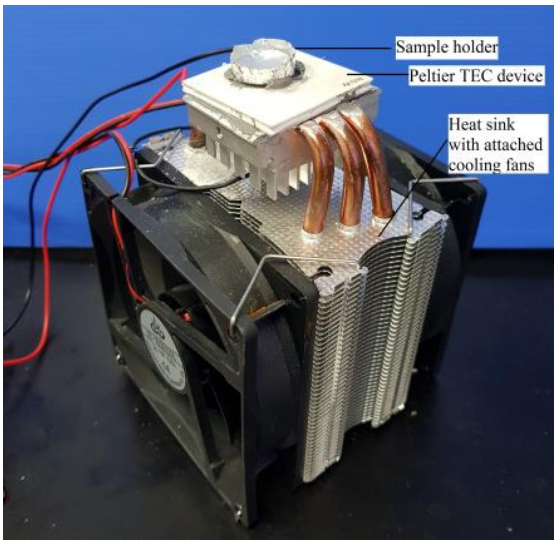

Fig. 1 Peltier TEC device with heat sink and sample holder.

\section{Experimental setup}

The experimental arrangement to investigate the emission from plasma induced in liquid and frozen $\mathrm{NaCl}$ solution is as shown in Fig. 2. The experimental setup was fixed for both experiments as it could affects the energy, spot size, and the beam pattern of the laser pulse, and thereby affecting the emission intensity [28]. The radiation from a Q-switched Nd:YAG laser (Mychway, model HR-LS450) operating at its fundamental wavelength of $1064 \mathrm{~nm}$ with $6 \mathrm{~ns}$ pulse duration and laser energy of $150 \mathrm{~mJ}$ was focused on the liquid and solidified sample surfaces. The laser energy was kept at $150 \mathrm{~mJ}$. This is to avoid the sample from cracking as the frozen sample surface tends to be a little mushy as the concentration is higher. Fig. 3 shows the comparison between the frozen sample surface of 0.5 and $2.0 \mathrm{~mol} / \mathrm{L}$ $\mathrm{NaCl}$ solution respectively. Laser frequency was kept fixed at $1 \mathrm{~Hz}$ to reduce emission variation between each shot due to the sample splashing. The system components were synchronized by a custom made control unit to gate the detector, thereby avoiding the delay between continuum and characteristic radiation.

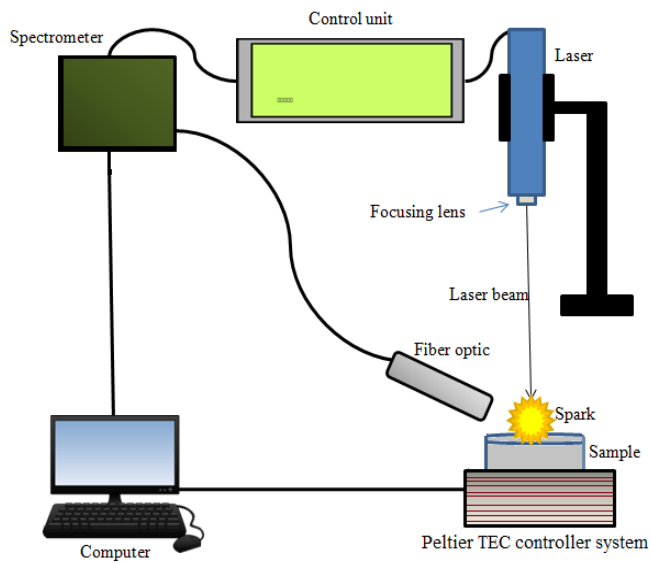

Fig. 2 Schematic diagram of the experimental setup.
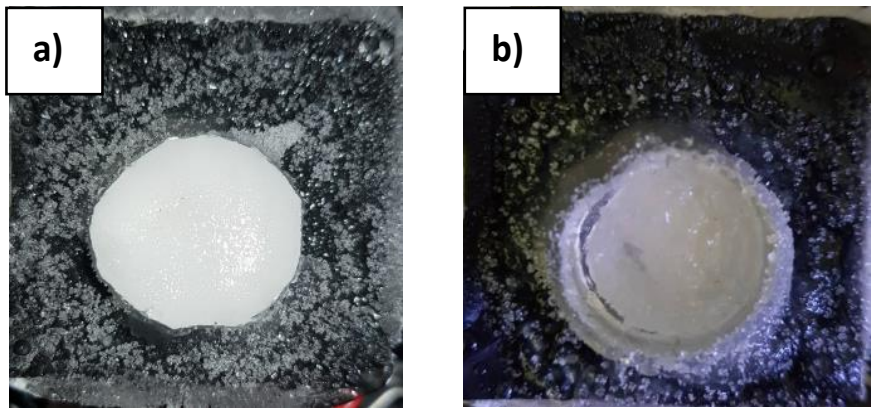

Fig. 3 Surface images of (a) $0.5 \mathrm{~mol} / \mathrm{L}$ with smooth surface and (b) 2.0 $\mathrm{mol} / \mathrm{L}$ with mushy surface of frozen $\mathrm{NaCl}$ solutions.

Plasma emission was collected at a distance of $2 \mathrm{~cm}$ and an angle of approximately $30^{\circ}$ with respect to the sample surface normal by a fiber optic. The captured emission was transmitted into a spectrometer (ASEQ-instruments, model LR1-version V2.1) and visualized in the computer by ASEQ Spectra software for further analysis. All spectra were obtained by accumulating 15 laser shots in order to minimize emission variation between each shot.

\section{RESULTS AND DISCUSSION}

\section{LIBS spectra}

Fig. 4 shows a representative LIBS spectra of $1.5 \mathrm{~mol} / \mathrm{L} \mathrm{NaCl}$ solution as frozen (upper) and liquid (lower) sample. Comparison of the two spectra clearly distinguishes the emision lines associated with 99.9\% vacuum salt. The assignments of the emission lines including $\mathrm{Na}$ I, Cl II, O II and H I were referred from the National Institute of Standards and Technology (NIST) Handbook of Basic Atomic Spectroscopic Data [29]. By referring to Fig. 4, the spectral emission obtained from the solidified (frozen) sample is more intense with less background noise unlike the liquid sample LIBS spectra. The emission enhancement happens probably due to increment of the ablation rate and the reduced sample splashing. 


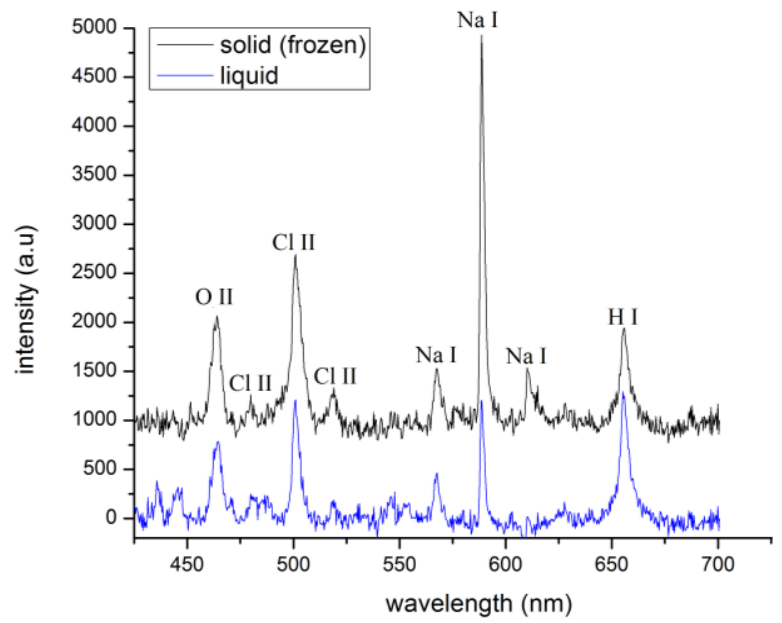

Fig. 4 Typical LIBS spectra from $1.5 \mathrm{~mol} / \mathrm{L}$ sample obtained from solid (frozen) and liquid samples. Offset has been added to allow comparison.

Fig. 5 and 6 further depict the spectral emission comparison between liquid and solidified sample. The offset and axis range were kept fixed to ease the comparison process between both respective plots. The Na I lines were observed around 569.00, 589.00 and 616.00 $\mathrm{nm}$. It should be noted that both of the Na emission doublets usually found around 569 and $589 \mathrm{~nm}$ were not completely resolved due to the limited sensitivity of the spectrometer used [11]. In this study, $\mathrm{Cl}$ is observed in the spectral region between 479.56 to $521.79 \mathrm{~nm}$ where several ionic chlorine lines appear.

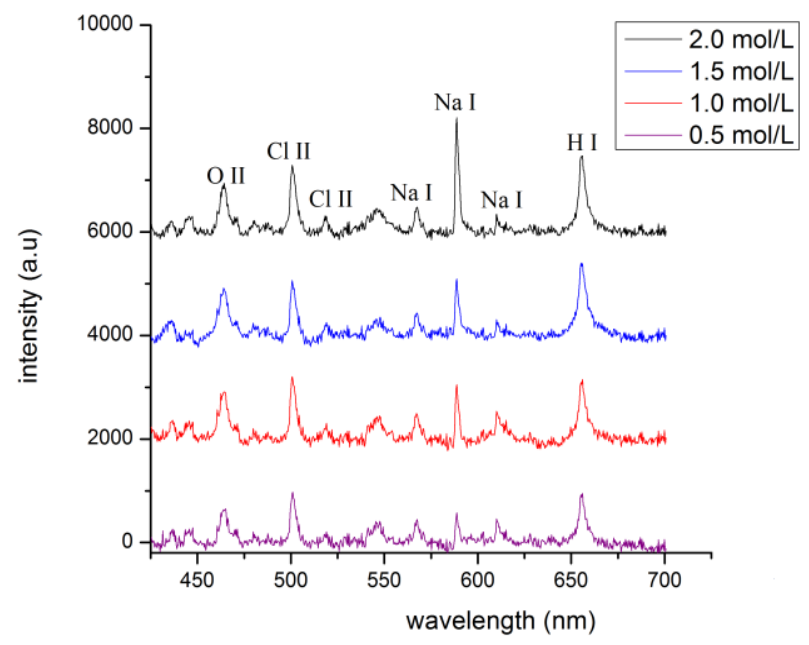

Fig. 5 Typical LIBS spectra obtained from all samples in its liquid form. Offset has been added to allow comparison.

The most intense sodium and chlorine lines were at 589.00 and $499.55 \mathrm{~nm}$ respectively. Meanwhile, the emission lines of $\mathrm{Na} \mathrm{I}$ $(616.00 \mathrm{~nm})$ and $\mathrm{Cl}$ II $(479.56$ and $521.79 \mathrm{~nm})$ disappeared in the noise of the LIBS spectra of the liquid samples and frozen samples with lower concentration of $\mathrm{NaCl}$.

The H I line at $656.27 \mathrm{~nm}$ was observed quite weakly in the frozen $0.5 \mathrm{~mol} / \mathrm{L} \mathrm{NaCl}$ sample but it was relatively strong in the LIBS spectrum of the other samples. This line indicates the ionic compounds in the form of hydrates contained in the solution samples [30]. Meanwhile, the O II line might originated from the solution samples [31] or the atmospheric oxygen. An overview of the spectral lines relevant for the analysis of this research is shown in Table 1. The line wavelength listed are based on the NIST handbook [29].

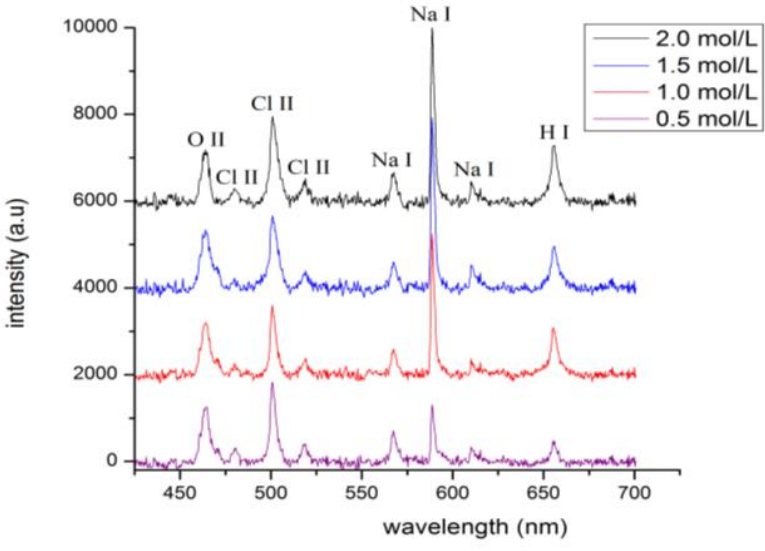

Fig. 6 Typical LIBS spectra obtained from all samples in its solid (frozen) form. Offset has been added to allow comparison.

\section{Signal-to-noise (SNR) ratio}

The signal-to-noise ratio (SNR) indicates the ratio between the transition peaks and the standard deviation of the background emission adjacent to the line [21]. To illustrate the relation between SNR, concentration and the sample phase, data points were taken from elements $\mathrm{Na}$ and $\mathrm{Cl}$ from $\mathrm{NaCl}$ solution with concentration between 0.5 to $2.0 \mathrm{~mol} / \mathrm{L}$, as shown in Fig. 7 and 8 . The studied transitions correspond to the $499.55 \mathrm{~nm}$ chlorine and $589.00 \mathrm{~nm}$ sodium lines. Ablation on solid (frozen) sample was proven to provide better SNR enhancement for both 499.55 and $589.00 \mathrm{~nm}$ lines, hence improving the detection sensitivity that will be explained in the next section.

SNR enhancement of frozen sample is due to more extensive excitation of the plasma, leading to higher emission intensity as observed in Fig. 4 and 6, thereby increasing the SNR. This is the opposite for liquid sample as most portion of the laser energy is used for liquid vaporisation with only a small remainder is available for plasma excitation, thus forming less efficient plasma [21,32].

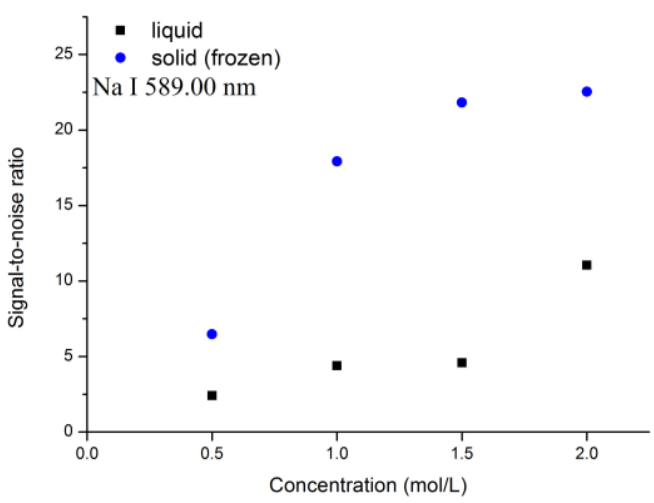

Fig. 7 Signal-to-noise ratio versus the sample concentration for $\mathrm{Na}$ $589.00 \mathrm{~nm}$ transition.

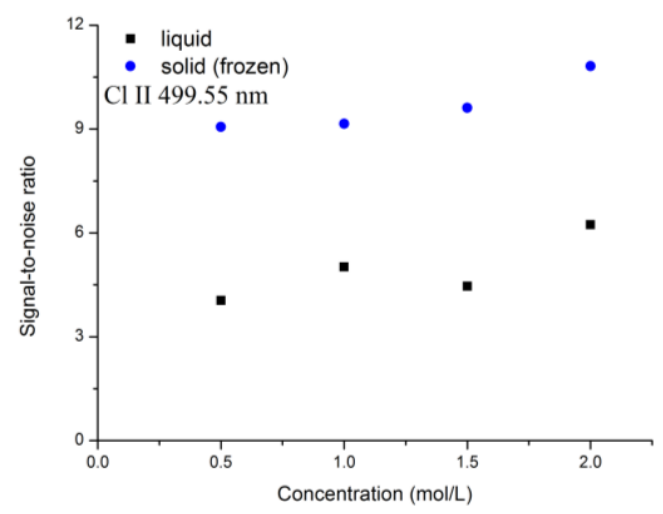

Fig. 8 Signal-to-noise ratio versus the sample concentration for $\mathrm{Cl}$ II $499.55 \mathrm{~nm}$ transition. 


\section{Limit-of-detection (LOD)}

The limit-of-detection (LOD) is equivalent to the lowest concentration of an element that can be detected by the LIBS system. The LOD of a species, as shown in Equation (1), is also a concentration value proportionate to the line intensity that is equal to three times the standard deviation of the background (standard deviation of the average of 20 points around the analyte peak), $\sigma$, with $\mathrm{S}$ is the slope of the calibration curve of a specific emission line.

$$
\mathrm{LOD}=3 \sigma / \mathrm{S}
$$

Fig. 9 and 10 show the $\mathrm{Na}$ and $\mathrm{Cl}$ calibration plots for LIBS analysis in water and solid (frozen) samples. The calibration curve is the relationship between the $\mathrm{NaCl}$ concentration and the chlorine or sodium intensity measured by LIBS. Although the LOD can also be determined from the SNR plots in the previous section, these calibration plots were included to better explain the LOD analysis. Prior to this analysis, both Cl II 499.55 and $\mathrm{Na}$ I $589.00 \mathrm{~nm}$ lines were chosen as best performing lines of each element due to their adequate linear response to the variation of the $\mathrm{NaCl}$ concentration. To assure the experiment repeatibility, each data point is an average of several rounds of measurements while the error bars correspond to the mean standard deviation.

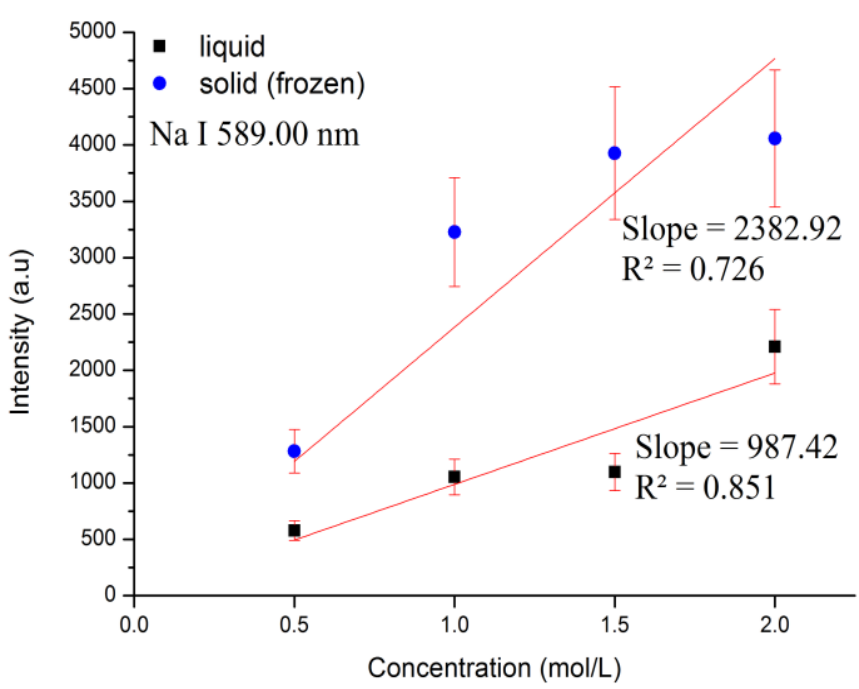

Fig. 9 Intensity versus the sample concentration for $\mathrm{Na}$ | $499.55 \mathrm{~nm}$.

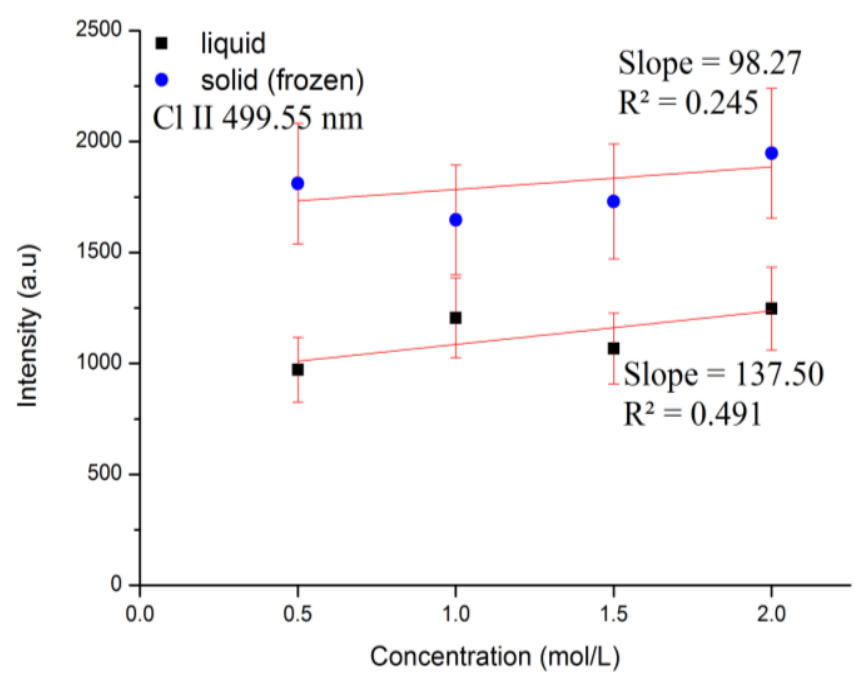

Fig. 10 Intensity versus the sample concentration for Cl II $499.55 \mathrm{~nm}$.
Table 1: Comparison of the limit-of-detection of elements obtained for liquid and solid (frozen) sample.

\begin{tabular}{cccc}
\hline Species & $\begin{array}{c}\text { NIST } \\
\text { wavelength } \\
(\mathbf{n m})\end{array}$ & $\begin{array}{c}\text { LOD (mol/L) } \\
\text { liquid sample }\end{array}$ & $\begin{array}{c}\text { LOD (mol/L) } \\
\text { solidified } \\
\text { sample }\end{array}$ \\
\hline $\mathrm{Na} \mathrm{I}$ & 589.00 & 0.23 & 0.12 \\
$\mathrm{CI} \mathrm{II}$ & 499.55 & 2.74 & 2.50 \\
\hline
\end{tabular}

\section{CONCLUSION}

The present study evaluated two different configurations for the analysis of liquid formulations of $\mathrm{NaCl}$ solutions using LIBS under equivalent experimental conditions: analysis on the surface of liquid in bulk and on the surface of its solidified (frozen) form. The solidified sample provided emission enhancement with better SNR when compared to the liquid sample mainly due to increased ablation rate and better coupling between the laser pulse and the sample.

Sample pre-treatment using TEC can also helps in preventing splashing and surface ripple that is usually related to the reduced performance of the liquid sample LIBS analysis. The LODs acquired from the solidified samples were also lower than those obtained from liquids. Lastly, this sample pre-treatment method is proven as a simple method that could maintain the sample in its freezing phase throughout the LIBS data acquisition, thereby providing emission enhancement, improved LIBS signal and limits of detection $(47.8 \%$ and $8.8 \%$ for $\mathrm{Na}$ and $\mathrm{Cl}$ respectively). It can be implemented for future LIBS analysis of liquid sample with various viscosity and thus replacing other common sample pre-treatment method in solidifying sample such as the conventional refrigerator or liquid nitrogen.

\section{ACKNOWLEDGEMENT}

This work was financially supported by the Universiti Teknologi Malaysia (UTM) under the Research University Grant [Vot No: Q.J130000.2626.13J97].

\section{REFERENCES}

[1] Winefordner, J. D., Gornushkin, I. B., Correll, T., Gibb, E., Smith, B. W., \& Omenetto, N. (2004). Comparing several atomic spectrometric methods to the super stars: special emphasis on laser induced breakdown spectrometry, LIBS, a future super star. Journal of Analytical Atomic Spectrometry, 19(9), 1061-1083.

[2] Williams, A. N., \& Phongikaroon, S. (2016). Elemental detection of cerium and gadolinium in aqueous aerosol using laser-induced breakdown spectroscopy. Applied Spectroscopy, 70(10), 1700-1708.

[3] Lee, Y.-I., Song, K., \& Sneddon, J. (2000). Laser-induced breakdown spectrometry. Huntington, New York: Nova Publishers.

[4] Papai, R., Sato, R. H., Nunes, L. C., Krug, F. J., \& Gaubeur, I. (2017). Melted paraffin wax as an innovative liquid and solid extractant for elemental analysis by laser-induced breakdown spectroscopy. Analytical Chemistry, 89(5), 2807-2815.

[5] Zhao, Y., Zhang, L., Zhao, S. X., Li, Y. F., Gong, Y., Dong, L., Ma, W. G., Yin, W. B., Yao, S. C., Lu, J. D., Xiao, L. T., \& Jia, S. T. (2016). Review of methodological and experimental LIBS techniques for coal analysis and their application in power plants in China. Frontiers of Physics, 11(6), 114211.

[6] Syvilay, D., Wilkie-Chancellier, N., Trichereau, B., Texier, A., Martinez, L., Serfaty, S., \& Detalle, V. (2015). Evaluation of the standard normal variate method for laser-induced breakdown spectroscopy data treatment applied to the discrimination of painting layers. Spectrochimica Acta Part B-Atomic Spectroscopy, 114, 38-45. 
[7] Peng, J. Y., Liu, F., Zhou, F., Song, K. L., Zhang, C., Ye, L. H., \& He, Y. (2016). Challenging applications for multi-element analysis by laser-induced breakdown spectroscopy in agriculture: A review. Trac-Trends in Analytical Chemistry, 85, 260-272.

[8] Harun, H. A., Zainal, R., \& Daud, Y. M. (2017). Analysing human nails composition by using laser induced breakdown spectroscopy. Sains Malaysiana, 46(1), 75-82.

[9] Jantzi, S. C., Motto-Ros, V., Trichard, F., Markushin, Y., Melikechi, N., \& De Giacomo, A. (2016). Sample treatment and preparation for laser-induced breakdown spectroscopy. Spectrochimica Acta Part B: Atomic Spectroscopy, 115, 52-63.

[10] Aguirre, M., Legnaioli, S., Almodóvar, F., Hidalgo, M., Palleschi, V., \& Canals, A. (2013). Elemental analysis by surface-enhanced laser-induced breakdown spectroscopy combined with liquid-liquid microextraction. Spectrochimica Acta Part B: Atomic Spectroscopy, 79, 88-93.

[11] St-Onge, L., Kwong, E., Sabsabi, M., \& Vadas, E. B. (2004) Rapid analysis of liquid formulations containing sodium chloride using laser-induced breakdown spectroscopy. Journal of Pharmaceutical and Biomedical Analysis, 36(2), 277-284.

[12] Lee, D.-H., Han, S.-C., Kim, T.-H., \& Yun, J.-I. (2011). Highly sensitive analysis of boron and lithium in aqueous solution using dual-pulse laser-induced breakdown spectroscopy. Analytical chemistry, 83(24), 9456-9461.

[13] Rai, N. K., \& Rai, A. (2008). LIBS - an efficient approach for the determination of $\mathrm{Cr}$ in industrial wastewater. Journal of Hazardous Materials, 150(3), 835-838.

[14] Aras, N., Yeşiller, S. Ü., Ateş, D. A., \& Yalçın, Ş. (2012). Ultrasonic nebulization-sample introduction system for quantitative analysis of liquid samples by laser-induced breakdown spectroscopy. Spectrochimica Acta Part B: Atomic Spectroscopy, 74, 87-94.

[15] Zhong, S.-L., Lu, Y., Kong, W.-J., Cheng, K., \& Zheng, R. (2016). Quantitative analysis of lead in aqueous solutions by ultrasonic nebulizer assisted laser induced breakdown spectroscopy. Frontiers of Physics, 11, 1-9.

[16] Cahoon, E. M., \& Almirall, J. R. (2012). Quantitative analysis of liquids from aerosols and microdrops using laser induced breakdown spectroscopy. Analytical Chemistry, 84(5), 22392244.

[17] Godwal, Y., Kaigala, G., Hoang, V., Lui, S.-L., Backhouse, C., Tsui, Y., \& Fedosejevs, R. (2008). Elemental analysis using micro laser-induced breakdown spectroscopy ( $\mu$ LIBS) in a microfluidic platform. Optics Express, 16(17), 12435-12445.

[18] Groh, S., Diwakar, P., Garcia, C., Murtazin, A., Hahn, D., \& Niemax, K. (2010). 100\% efficient sub-nanoliter sample introduction in laser-induced breakdown spectroscopy and inductively coupled plasma spectrometry: Implications for ultralow sample volumes. Analytical Chemistry, 82(6), 25682573.

[19] Motto-Ros, V. (2015). Characteristics of indirect laser-induced plasma from a thin film of oil on a metallic substrate. Frontiers of Physics, 10(2), 231-239.

[20] Xiu, J., Bai, X., Negre, E., Motto-Ros, V., \& Yu, J. (2013). Indirect laser-induced breakdown of transparent thin gel layer for sensitive trace element detection. Applied Physics Letters, 102(24), 244101.

[21] Musazzi, S., \& Perini, U. (2014). LIBS Analysis of Liquids and of Materials Inside Liquids. Laser-Induced Breakdown Spectroscopy: Theory and Applications (pp. 195-223). Berlin, Heidelberg: Springer.

[22] Cáceres, J., López, J. T., Telle, H., \& Ureña, A. G. (2001). Quantitative analysis of trace metal ions in ice using laserinduced breakdown spectroscopy. Spectrochimica Acta Part B: Atomic Spectroscopy, 56(6), 831-838.

[23] Sobral, H., Sanginés, R., \& Trujillo-Vázquez, A. (2012). Detection of trace elements in ice and water by laser-induced breakdown spectroscopy. Spectrochimica Acta Part B: Atomic Spectroscopy, 78, 62-66.

[24] Lazic, V., Colao, F., Fantoni, R., Spizzichino, V., \& Jovićević, S. (2007). Underwater sediment analyses by laser induced breakdown spectroscopy and calibration procedure for fluctuating plasma parameters. Spectrochimica Acta Part B. Atomic Spectroscopy, 62(1), 30-39.

[25] El-Hussein, A., Kassem, A., Ismail, H., \& Harith, M. (2010). Exploiting LIBS as a spectrochemical analytical technique in diagnosis of some types of human malignancies. Talanta, 82(2), 495-501.

[26] Hossain, M. A., Canning, J., Yu, Z. K., Ast, S., Rutledge, P. J., Wong, J. K. H., Jamalipour, A., \& Crossley, M. J. (2017). Timeresolved and temperature tuneable measurements of fluorescent intensity using a smartphone fluorimeter. Analyst, 142(11), 1953-1961.

[27] Nemati, A., Nami, H., Yari, M., Ranjbar, F., \& Kolvir, H. R. (2016). Development of an exergoeconomic model for analysis and multi-objective optimization of a thermoelectric heat pump. Energy Conversion and Management, 130, 1-13.

[28] Eto, S., \& Fujii, T. (2016). Laser-induced breakdown spectroscopy system for remote measurement of salt in a narrow gap. Spectrochimica Acta Part B: Atomic Spectroscopy, 116, 51-57.

[29] Sansonetti, J. E., \& Martin, W. C. (2005). Handbook of basic atomic spectroscopic data. Journal of Physical and Chemical Reference Data, 34(4), 1559-2259.

[30] Park, G., Yoo, H., Gong, Y., Cui, S., Nam, S. H., Ham, K. S., Yoo, J., Han, S. H., \& Lee, Y. (2015). Feasibility of rapid classification of edible salts by a compact low-cost laser-induced breakdown spectroscopy device. Bulletin of the Korean Chemical Society, 36(1), 189-197.

[31] Guanhong, W., Duixiong, S., Maogen, S., \& Chenzhong, D. (2014). LIBS detection of heavy metal elements in liquid solutions by using wood pellet as sample matrix. Plasma Science and Technology, 16(6), 598.

[32] Cremers, D. A., Radziemski, L. J., \& Loree, T. R. (1984). Spectrochemical analysis of liquids using the laser spark. Applied Spectroscopy, 38(5), 721-729.

[33] Rezaei, F., Karimi, P., \& Tavassoli, S. (2014). Effect of selfabsorption correction on LIBS measurements by calibration curve and artificial neural network. Applied Physics B, 114(4), 591-600. 